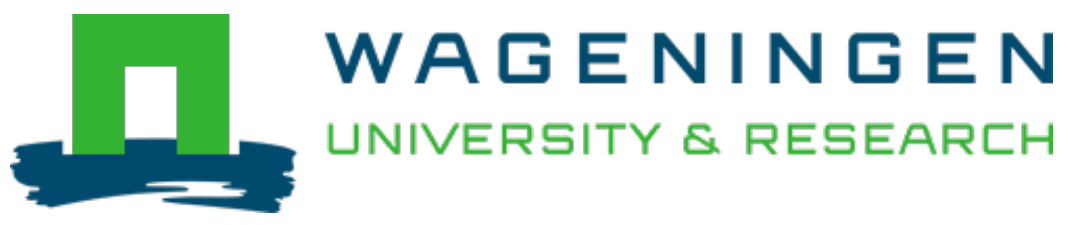

\title{
Strategies to compensate for undesired gritty sensations in foods
}

Food Quality and Preference

Santagiuliana, Marco; Broers, Layla; Marigómez, Inés Sampedro; Stieger, Markus; Piqueras-Fiszman, Betina et al

https://doi.org/10.1016/j.foodqual.2019.103842

This article is made publicly available in the institutional repository of Wageningen University and Research, under the terms of article $25 \mathrm{fa}$ of the Dutch Copyright Act, also known as the Amendment Taverne. This has been done with explicit consent by the author.

Article $25 \mathrm{fa}$ states that the author of a short scientific work funded either wholly or partially by Dutch public funds is entitled to make that work publicly available for no consideration following a reasonable period of time after the work was first published, provided that clear reference is made to the source of the first publication of the work.

This publication is distributed under The Association of Universities in the Netherlands (VSNU) 'Article $25 \mathrm{fa}$ implementation' project. In this project research outputs of researchers employed by Dutch Universities that comply with the legal requirements of Article $25 \mathrm{fa}$ of the Dutch Copyright Act are distributed online and free of cost or other barriers in institutional repositories. Research outputs are distributed six months after their first online publication in the original published version and with proper attribution to the source of the original publication.

You are permitted to download and use the publication for personal purposes. All rights remain with the author(s) and / or copyright owner(s) of this work. Any use of the publication or parts of it other than authorised under article $25 \mathrm{fa}$ of the Dutch Copyright act is prohibited. Wageningen University \& Research and the author(s) of this publication shall not be held responsible or liable for any damages resulting from your (re)use of this publication.

For questions regarding the public availability of this article please contact openscience.library@wur.nl 


\title{
Strategies to compensate for undesired gritty sensations in foods
}

\author{
Marco Santagiuliana ${ }^{\mathrm{a}, \mathrm{b}}$, Layla Broers ${ }^{\mathrm{b}}$, Inés Sampedro Marigómez ${ }^{\mathrm{b}}$, Markus Stieger ${ }^{\mathrm{a}, \mathrm{c}, \mathrm{d}}$, \\ Betina Piqueras-Fiszman ${ }^{\mathrm{e}}$, Elke Scholten ${ }^{\mathrm{b}, *}$ \\ a TiFN, PO Box 557, 6700 AN Wageningen, The Netherlands \\ ${ }^{\mathrm{b}}$ Physics and Physical Chemistry of Foods, Wageningen University, PO Box 17, 6700 AA Wageningen, The Netherlands \\ ${ }^{\mathrm{c}}$ Food Quality and Design, Wageningen University, PO Box 17, 6700 AA Wageningen, The Netherlands \\ ${ }^{\mathrm{d}}$ Division of Human Nutrition and Health, Wageningen University, PO Box 17, 6700 AA Wageningen, The Netherlands \\ ${ }^{\mathrm{e}}$ Marketing and Consumer Behaviour, Department of Social Sciences, Wageningen University, PO Box 8130, 6700 EW Wageningen, The Netherlands
}

\section{A R T I C L E I N F O}

\section{Keywords:}

Texture perception

Composite foods

Microparticles

Grittiness

TDS

Multiparticulate

\begin{abstract}
A B S T R A C T
This study investigated whether the addition of macroparticles or fat can be used to compensate for negative texture sensations in quark. Cellulose beads were added as model microparticles (1.5\% w/w; average size: $263 \mu \mathrm{m})$ to quark ( $0 \%$ fat) to induce unpleasant gritty sensations. The addition of microparticles to quark significantly increased grittiness and dryness, while creaminess and liking decreased. Three strategies were explored to reduce the impact of unpleasant gritty sensations on consumer perception: two strategies involved the addition of macroparticles (granola or peach gel pieces); the third one consisted of increasing the fat content of the quark $(4.4$ and $8.8 \% \mathrm{w} / \mathrm{w})$. For all three strategies, grittiness caused by microparticles did not significantly decrease when macroparticles or fat were present. Addition of peach gel pieces to quark with microparticles did not increase liking. When granola pieces were added to quark containing microparticles, liking increased significantly despite that grittiness was still perceived. Temporal Dominance of Sensations (TDS) revealed that addition of granola pieces caused prolonged dominance of positive, crunchy sensations and minimized dominance of negative, gritty sensations. The addition of fat did not lead to a significant increase in liking of quark, although when a medium amount of fat was added (4.4\%), it also did not decrease liking significantly. This was probably due to an effective hedonic compensation triggered by more positive sensations (i.e. sweetness). We conclude that addition of crunchy granola pieces or fat can be used as strategies to shift and increase dominance of positive and liked attributes, leading to an increase of overall liking, although negative sensations (grittiness) caused by microparticles are still perceived. This approach could be used to compensate for undesired texture sensations in different types of foods, such as high protein foods.
\end{abstract}

\section{Introduction}

Grittiness, graininess, and roughness are undesired textural sensations in food products, which decrease overall food quality (Engelen, De Wijk, et al., 2005; Krzeminski et al., 2013; Lopez et al., 2018). These sensations are usually caused by the presence of microscopic particles of different kinds and origins. Such microparticles can be either naturally present in food (e.g. protein aggregates in dairy products or in protein enriched liquid foods, fibres) or deliberately added to deliver pharmaceutical compounds upon oral consumption (e.g. multiparticulate formulations composed by cellulose beads; Lopez et al., 2016; Rohart, Sieffermann, \& Michon, 2015).

Many studies investigated the effect of microparticle properties on detection thresholds and grittiness perception. Microparticle size, hardness, shape, and concentration have been reported to be key factors influencing texture perception of various foods such as custards and soups (Engelen, Van Der Bilt, Schipper, \& Bosman, 2005; Petersson, Eliasson, Tornberg, \& Bergenståhl, 2013; Sainani, Vyas, \& Tong, 2004; Santagiuliana, Christaki, Piqueras-Fiszman, Scholten, \& Stieger, 2018; Tyle, 1993). Gritty sensations increase with an increase in particle size, hardness, and surface roughness. A direct modification of these particlerelated properties (e.g. reduction in particle size) remains the most effective strategy to decrease the undesired sensations of grittiness (Modler, Yiu, Bollinger, \& Kalab, 1989; Petersson et al., 2013). Nevertheless, such adjustments are not always possible to implement due to various technical limitations during processing or when microparticles are added after the production process. For instance, novel drug therapies require that patients add drug-loaded particulates to their

\footnotetext{
* Corresponding author.

E-mail address: elke.scholten@wur.nl (E. Scholten).
} 
food products. These forms of oral solid dosage do not allow product modifications that can prevent a gritty sensations (Lopez et al., 2016, 2018; Marconati, Lopez, Tuleu, Orlu, \& Ramaioli, 2019) and, therefore, other strategies have to be used to decrease undesired perceptions caused by the presence of microparticles.

When matrix modifications in foods are possible, a common strategy used to prevent microparticle detection consists of increasing the viscosity of the continuous phase. A higher matrix viscosity lowers consumers' ability to perceive microparticles suspended in it (Engelen, De Wijk, et al., 2005; Liu, Stieger, van der Linden, \& van de Velde, 2016; Lopez et al., 2016). Alternatively, there are indications that fat addition can also lower the detectability of microparticles (typically $25-150 \mu \mathrm{m}$ ), as fat provides lubrication to foods. de Wijk and Prinz (2005) demonstrated that higher fat contents in semi-solid foods can significantly decrease rough sensations and increase creaminess. In the case of custard, this was attributed to the low friction coefficient caused by the presence of dispersed fat droplets. Perception of microparticles $(<200 \mu \mathrm{m})$ in foods can thus be modulated by modifying matrix consistency and/or adding fat. However, very little is known about the ability of fat to decrease perception of microparticles in the $>200 \mu \mathrm{m}$ size range. Additionally, since modifications of matrix consistency are not possible or desired in all food products, alternative solutions are required to reduce unpleasant gritty sensations.

With respect to the investigation of microparticle detection and gritty perception in foods, prior work dealt with relatively simple foods in which participants might have focused on a limited number of sensory attributes. Many foods, however, are characterized by the presence of multiple components (e.g. presence of chocolate chips in cookies or noodles in soups). For such heterogeneous foods, the perception of specific sensory characteristics becomes more complicated as the sensations provoked by the different components might direct consumers' attention unevenly. Possible novel strategies to prevent perception of undesired attributes might be developed by combining different components in a product. Consumers commonly add different types of particles to a variety of foods, for example, croutons or vegetable pieces to soups or granola and fruit pieces to dairy products such as yoghurt and quark. The presence of macroparticles not only provides contrasting textural and flavour sensations that contribute positively to product liking (Hyde \& Witherly, 1993; Santagiuliana, Bhaskaran, Scholten, Piqueras-Fiszman, \& Stieger, 2019; Santagiuliana, van den Hoek, Stieger, Scholten, \& Piqueras-Fiszman, 2019; Szczesniak \& Kahn, 1984), but also influences dynamic sensory perception and oral processing behaviour (Devezeaux de Lavergne et al., 2015; James, 2018; Larsen, Tang, Ferguson, Morgenstern, \& James, 2016; Santagiuliana, Piqueras-Fiszman, van der Linden, Stieger, \& Scholten, 2018; Tang, Larsen, Ferguson, \& James, 2017; Tarrega, Marcano, \& Fiszman, 2016; van Eck, Fogliano, Galindo-Cuspinera, Scholten, \& Stieger, 2018; van Eck, Hardeman, Karatza, Fogliano, \& Scholten, 2019). Multiple elements in foods can lead to differences in oral manipulation (Kim et al., 2015). When a combination of spherical particles varying in size (4 and $15 \mathrm{~mm}$ diameter) is present in foods, larger particles are chewed significantly more than smaller particles, and therefore oral processing was dominated by the larger particles. The authors suggested that an altered chewing behaviour by the presence of such particles varying in size, might be used to prevent undesired sensory effects caused by the presence of small particles.

To the best of our knowledge, it is not known how the addition of macroparticles or fat can alter the perception of foods containing microparticles $(>200 \mu \mathrm{m}$ ), and whether such an addition has the potential to compensate for undesired texture sensations such as grittiness. We hypothesise that macroparticles direct the attention of consumers away from undesired gritty sensations towards desired positive texture sensations and thus prevent a decrease in liking. Addition of macroparticles with contrasting mechanical properties (i.e. soft or hard fruit pieces) or characterized by positive and dominant textural sensations (e.g. crunchy granola pieces) might alter the perception and hedonic response of the consumer in different directions. Furthermore, we hypothesise that presence of fat in foods containing microparticles might change the textural properties in the product matrix by providing extra lubrication and positive perception (i.e. creaminess) that could reduce perceived grittiness.

To test these hypotheses, we selected a common, commercially available dairy product (i.e. quark) in which not only the perception of microparticles is associated to a product defect, but also the addition of different macroparticles, such as fruit and granola, is quite common during consumption. Therefore, this study aimed to investigate whether the addition of macroscopic particles or fat to quark can be used to compensate for negative texture sensations (grittiness) by either psychological (e.g. increasing dominance of other attributes; shifting attention) or physical (e.g. lubricative effects of fat) mechanisms. Microscopic cellulose beads $(263 \mu \mathrm{m})$ were added to quark to induce gritty sensations. Static (ranking test) and dynamic (Temporal Dominance of Sensation) sensory properties and liking of quarks containing added fat or macroparticles (peach gel pieces and granola pieces) varying in mechanical properties (soft, hard) were investigated. Ranking tests were used to evaluate whether the addition of fat or macroparticles can prevent or reduce grittiness sensations in quark and to quantify the effect of microparticle addition on the perceived product sensory profile. Temporal Dominance of Sensation (TDS) was used to assess whether the dominance of positive sensations caused by the addition of macroparticles to quark containing microparticles can be increased so that the dominance of undesired gritty sensations is suppressed.

\section{Materials and methods}

In this study, the physical properties (viscosity of quark; Section 2.3.1) and mechanical properties of macroparticles (Section 2.3.2) were quantified. Two separate sensory tests were performed to characterize the participants' response to the stimuli: a ranking test and hedonic evaluation (Section 2.4) and a Temporal dominance of Sensation (TDS) test (Section 2.5).

\subsection{Materials}

Quark, a spoonable curd cheese ("Milde kwark naturel") with two different fat contents, was provided by FrieslandCampina (FrieslandCampina, Wageningen, The Netherlands) as a representative for a soft semi-solid dairy product for this study. Low-fat $(0.1 \%$ fat, $10.3 \%$ protein, $2.8 \%$ sugars, $0.1 \%$ salt $)$ and full-fat quark $(8.8 \%$ fat, $8.8 \%$ protein, $2.7 \%$ sugars, $0.1 \%$ salt) were used. Both low-fat and fullfat commercially available quarks were chosen because of their smooth texture and homogeneous structure, as no particles or lumps are present in either of them. Microcrystalline cellulose particles (Cellets ${ }^{\circledR}$ 263) were kindly donated by Harke Pharma (Mülheim an der Ruhr, Germany). Granola honey/coconut with hazelnuts (pieces with an average diameter of $\sim 6 \mathrm{~mm}$ ) was kindly donated by Bio-familia AG (Sachseln, Switzerland). Canned peaches (PLUS, Utrecht, The Netherlands), strawberry flavoured yoghurt (Almhof ${ }^{\circledast}$, Veenendaal, The Netherlands) and cornflakes (Jumbo, Veghel, The Netherlands) were purchased from a local supermarket. Agar was purchased from Caldic Ingredients B.V. (Rotterdam, The Netherlands). Holland Ingredients B.V. (Meppel, The Netherlands) kindly provided annatto (orange food colourant, WS $2.5 \%$, E160b). Titanium dioxide $\left(\mathrm{TiO}_{2}, \mathrm{E} 171\right)$ and riboflavin (yellow food colourant, 10\% PWS, E101) were provided by Pomona Aroma B.V. (Hedel, The Netherlands).

\subsection{Sample preparation}

\subsubsection{Quark containing microparticles}

Microcrystalline cellulose beads (average diameter: $263 \mu \mathrm{m}$; concentration: $1.5 \% \mathrm{w} / \mathrm{w}$ ) were added to fat-free homogeneous quark to 
induce gritty sensations. Grittiness was ensured by the crystalline and not-deformable structure (i.e. hard beads) of the cellulose beads since particle hardness largely determines their detectability and perception (Chojnicka-Paszun, Doussinault, \& De Jongh, 2014; Santagiuliana, Christaki, et al., 2018; Tyle, 1993). The size and concentration of added particles were chosen based on feasibility tests (data not shown) and available literature to ensure that participants detect the particles and perceive them as gritty sensations. The microparticles and the continuous matrix were both white, and therefore the particles were not visually detectable. The microparticles were incorporated into the product by manually mixing them up to a max. of 3 days before participant evaluation; prior work indicated that water absorption of microcrystalline cellulose particles over this time period is negligible (Lopez et al., 2016; Santagiuliana, Marigómez, et al., 2019), so both particles and matrix properties are not affected.

\subsubsection{Quark with added granola pieces}

Granola pieces varying in hardness (soft/hard) were used as macroscopic particles and added to quark. Hard granola was the commercially available product. To obtain soft granola pieces, granola was moistened using an electric oven (Rational, Mod. SCC101, Barcelona, Spain) set at $40{ }^{\circ} \mathrm{C}$ with $100 \%$ relative humidity for $1 \mathrm{~h}$. Such a treatment provided the granola with a water absorption of $27 \pm 2 \%(\mathrm{w} / \mathrm{w})$. Both soft and hard granola pieces were added $(10 \% \mathrm{w} / \mathrm{w})$ to low-fat quark and manually mixed just before providing each sample to the participants.

\subsubsection{Quark with added peach gel pieces}

The second macroparticle type used in this study was peach gel pieces varying in hardness (soft/hard). Peach juice was extracted from canned peaches using a hand blender (Braun MQ 745, Kronberg im Taunus, Germany) and centrifuged at $3900 \mathrm{~g}$ for $20 \mathrm{~min}$ (Beckman Coulter Allegra X-30R, Fullerton, USA). The obtained supernatant was combined with agar, $\mathrm{TiO}_{2}(0.039 \% \mathrm{w} / \mathrm{w})$, and the food colourants riboflavin and annatto. A $1.4 \%(\mathrm{w} / \mathrm{w})$ and $3.6 \%(\mathrm{w} / \mathrm{w})$ agar concentration was used to obtain soft and hard gels, respectively. The amount of colourants was also adjusted to ensure similar visual appearance independently from the amount of gelling agent used. Specifically, riboflavin and annatto were added in a concentration of $0.025 \%(\mathrm{w} / \mathrm{w})$ and $0.024 \%(\mathrm{w} / \mathrm{w})$ for soft gels, while concentrations of $0.024 \%(\mathrm{w} / \mathrm{w})$ and $0.023 \%(\mathrm{w} / \mathrm{w})$ were used for hard gels. Solutions were heated under continuous stirring in a water bath at $95^{\circ} \mathrm{C}$ for $45 \mathrm{~min}$, and subsequently poured in disposable plastic containers. After cooling on ice for $1 \mathrm{~h}$, the obtained gels were cut in cubes of $7 \times 7 \times 7 \mathrm{~mm}$ using a mandolin (Michel BRAS, Laguiole, France). The resulting peach gel pieces resembled the appearance and shape of commercially available canned peach cubes, which are often added to dairy products. The peach gel pieces were stored at $4{ }^{\circ} \mathrm{C}$ for a maximum of one week. Similar to the granola pieces, peach gel pieces were combined $(10 \% \mathrm{w} /$ w) with quark and manually mixed at the moment of serving the samples.

\subsubsection{Quark varying in fat content}

Fat content in quark was varied from 0 to 4.4 and $8.8 \% \mathrm{w} / \mathrm{w}$. For this purpose, commercially available low-fat quark $(<0.1 \% \mathrm{w} / \mathrm{w})$ and full-fat quark $(8.8 \% \mathrm{w} / \mathrm{w})$ were used, and the mid-fat quark $(4.4 \% \mathrm{w} /$ w) was obtained by combining the low- and full-fat quark in a 50:50 ratio.

\subsection{Sample characterization}

\subsubsection{Viscosity of quark}

The viscosity of homogeneous quarks (low-fat, mid-fat, and full-fat) was determined using a rheometer (Anton Paar GmbH, MCR-302). Measurements were performed in triplicate at $4{ }^{\circ} \mathrm{C}$, using a shear rate ranging from 0 to $1000 \mathrm{~s}^{-1}$ in a total time interval of $2.5 \mathrm{~min}$. The rheometer was operated in rotational mode with a C-CC17/T200/Ti cup (diameter of $18.08 \mathrm{~mm}$ ) and a CC17/Ti inner cylinder (diameter $16.66 \mathrm{~mm}$ and length of $24.94 \mathrm{~mm}$ ). A resting period of $5 \mathrm{~min}$ before each measurement was used to obtain equilibrium. Quarks varying in fat content showed no significant differences in viscosity at the same shear rate. All quarks were shear thinning as the apparent viscosity decreased significantly $(p<0.05)$ with increasing shear rate. At shear rates $\dot{\gamma}$ of $10 \mathrm{1} / \mathrm{s}$, the low-, mid- and full-fat quark had an apparent viscosity, $\eta$, of $4.1 \pm 0.1 \mathrm{~Pa} \mathrm{~s}, 4.6 \pm 1.0 \mathrm{~Pa} \mathrm{~s}$, and $4.6 \pm 0.9 \mathrm{~Pa} \mathrm{~s}$, respectively. When the shear rate, $\dot{\gamma}$, was increased to 1001 /s, quarks presented an apparent viscosity, $\eta$, of $2.3 \pm 0.1 \mathrm{~Pa}$ s, $2.5 \pm 0.4 \mathrm{~Pa}$ and 2.4 \pm 0.4 Pa s for low-, mid- and full-fat samples, respectively. The variation in viscosity between quark samples was limited and was therefore assumed not to influence grittiness perception.

\subsubsection{Mechanical properties of granola and peach gel pieces}

Mechanical properties of granola and peach gel pieces were characterized by cutting tests. A Texture Analyser (TA.XT plus, Stable Micro Systems-SMS) equipped with a "Light Knife Blade" (20 mm height, $60 \mathrm{~mm}$ width, $3 \mathrm{~mm}$ max thickness, tip angle of $60^{\circ}$; Stable Micro Systems-SMS) and a $5 \mathrm{~kg}$ load cell was used. A crosshead velocity of $1 \mathrm{~mm} / \mathrm{s}$ and a final strain of $90 \%$ was selected. From the force-distance curve, the max peak forces $(\mathrm{N})$ at fracture were calculated. Average values were calculated based on a minimum of 10 measurements. The results of the cutting test on macroparticles highlighted that hard granola pieces had significantly higher $(p<0.05)$ max peak forces of $16 \pm 7 \mathrm{~N}$ than the soft pieces with $10 \pm 4 \mathrm{~N}$. Similarly, hard peach gel pieces had significant higher $(p<0.05)$ mean peak force $(0.45 \pm 0.07 \mathrm{~N})$ than soft peach gel pieces $(0.01 \pm 0.01 \mathrm{~N})$. These results indicate that for both macroparticles, the soft and hard versions were different in mechanical properties. In addition, granola pieces required considerably more cutting force than the peach gel pieces, and can therefore be considered much harder.

\subsection{Ranking test and hedonic evaluation}

\subsubsection{Participants}

One hundred and fourteen untrained participants $(n=114,94$ female, 20 male; average age: $22.3 \pm 2.3 y r s)$ completed the sensory evaluation (ranking test) and hedonic evaluation. Participants were screened based on several selection criteria age (between 18 and 35 years), health status (absence of recognized diseases), and BMI $\left(18.5-26.5 \mathrm{~kg} / \mathrm{m}^{2}\right)$. Exclusion criteria were allergies, pregnancy, smoking habit, missing teeth (except wisdom teeth), dental implants, or deficits in taste or smell. All participants gave written informed consent at the beginning of the sensory test and were requested to abstain from eating $1 \mathrm{~h}$ before each session.

\subsubsection{Method}

Participants attended one familiarization session of $30 \mathrm{~min}$ and two test sessions of $1 \mathrm{~h}$ each in 3 non-consecutive days. During the familiarization session, participants received an explanation on how to perform the sensory evaluation. During the first test session, $30 \mathrm{~g}$ of each of the eleven quark samples was delivered, as shown in Table 1 , and they evaluated the samples on overall liking, flavour liking, and texture liking on a nine-hedonic point scale ranging from "Dislike extremely" (1) to "Like extremely" (9). Samples were presented in a monadic randomized counterbalanced sequence.

In the second test session, participants performed ranking tests on the three sets of products, namely the quarks containing granola, peach and fat (Table 1). Each set was composed of five samples: (1) a homogeneous plain quark (LF); (2) quark containing microparticles (LF $\mid \mathrm{mp}$ ), which were used as reference samples; (3-4) two quarks containing microparticles and either fat, peach gels or granola varying in concentration or hardness; and (5) one quark with either fat $(8.8 \%$ $\mathrm{w} / \mathrm{w}$ ), peach (soft) or granola (hard) without the presence of 
Table 1

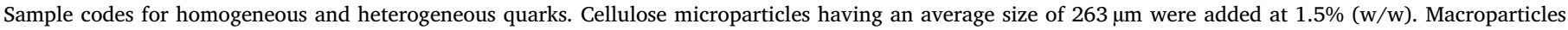
having an average size of $>6 \mathrm{~mm}$ (granola or peach gel pieces) were added at $10 \%(\mathrm{w} / \mathrm{w})$.

\begin{tabular}{|c|c|c|c|c|c|c|c|}
\hline \multirow[t]{2}{*}{ Product code } & \multirow{2}{*}{$\begin{array}{l}\text { Fat } \\
(\% \mathrm{w} / \mathrm{w})\end{array}$} & \multirow[t]{2}{*}{ Microparticles } & \multirow[t]{2}{*}{ Macroparticles } & \multicolumn{3}{|c|}{ Ranking product set } & \multirow[t]{2}{*}{ TDS } \\
\hline & & & & Granola & Peach & Fat & \\
\hline LF & $<0.1$ & No & - & $\checkmark$ & $\checkmark$ & $\checkmark$ & $\checkmark$ \\
\hline $\mathrm{LF} \mid \mathrm{mp}$ & $<0.1$ & Yes & - & $\checkmark$ & $\checkmark$ & $\checkmark$ & $\checkmark$ \\
\hline $\mathrm{LF}|\mathrm{mp}| \mathrm{SG}$ & $<0.1$ & Yes & Soft Granola & $\checkmark$ & & & $\checkmark$ \\
\hline $\mathrm{LF}|\mathrm{mp}| \mathrm{HG}$ & $<0.1$ & Yes & Hard Granola & $\checkmark$ & & & $\checkmark$ \\
\hline $\mathrm{LF} \mid \mathrm{HG}$ & $<0.1$ & No & Hard Granola & $\checkmark$ & & & \\
\hline $\mathrm{LF}|\mathrm{mp}| \mathrm{SP}$ & $<0.1$ & Yes & Soft Peach & & $\checkmark$ & & $\checkmark$ \\
\hline $\mathrm{LF}|\mathrm{mp}| \mathrm{HP}$ & $<0.1$ & Yes & Hard Peach & & $\checkmark$ & & $\checkmark$ \\
\hline $\mathrm{LF} \mid \mathrm{SP}$ & $<0.1$ & No & Soft Peach & & $\checkmark$ & & \\
\hline $\mathrm{MF} \mid \mathrm{mp}$ & 4.4 & Yes & - & & & $\checkmark$ & $\checkmark$ \\
\hline $\mathrm{FF} \mid \mathrm{mp}$ & 8.8 & Yes & - & & & $\checkmark$ & $\checkmark$ \\
\hline $\mathrm{FF}$ & 8.8 & No & - & & & $\checkmark$ & \\
\hline
\end{tabular}

Table 2

Sensory descriptors and definitions used for the ranking and TDS test. Check marks indicate that the term was used for the specific test type.

\begin{tabular}{|c|c|c|c|}
\hline Descriptor & Ranking & TDS & Definition \\
\hline \multicolumn{4}{|l|}{ Texture } \\
\hline Creaminess & $\checkmark$ & $\checkmark$ & Sensation of a thick, smooth and velvety texture in the mouth. \\
\hline Crunchiness & $\checkmark$ & $\checkmark$ & The sound of a low-pitched, longer sounding crushing noise during mastication. \\
\hline Dryness & $\checkmark$ & $\checkmark$ & Perception of a dry feeling in the mouth. \\
\hline Hardness & $\checkmark$ & $\checkmark$ & Force required to compress and/or break the sample (or its components) between the teeth. \\
\hline Sandy/gritty & $\checkmark$ & $\checkmark$ & The perception of small (sand-like) particles in the mouth. \\
\hline \multicolumn{4}{|l|}{ Flavour } \\
\hline Overall flavour intensity & $\checkmark$ & & Perception of product overall flavour. \\
\hline Peach flavour & & $\checkmark$ & Perception of peach aroma \\
\hline Dairy flavour & & $\checkmark$ & Perception of milky aroma \\
\hline Wheat flavour & & $\checkmark$ & Perception of wheat aroma \\
\hline Sourness & $\checkmark$ & $\checkmark$ & Perception of a sour flavour in the mouth. \\
\hline Sweetness & $\checkmark$ & $\checkmark$ & Perception of a sweet flavour in the mouth (sugar like). \\
\hline
\end{tabular}

microparticles. Participants were asked to rank the five samples of each set on a line (100 mm VAS scale; verbal anchors: "not at all" and "very much") with respect to different attributes (see Table 2). Participants were allowed to re-taste previous samples as often as they wanted. Rank intensity scores for each product were obtained (Kim \& O'Mahony, 1997). Attributes and definitions were established and tested during previous feasibility tests. Due to a faulty set-up of the digital questionnaire, data for the attributes dryness and flavour intensity were not recorded for the quarks with fat, and are only available for the sets with granola and peach gel pieces. No ties were allowed and the order of attributes was randomized per participant. Serving order of each product set was counterbalanced. Sample evaluation was performed in sensory booths at $20^{\circ} \mathrm{C}$ and under normal light conditions. Quarks were served at $4{ }^{\circ} \mathrm{C}$ in plastic cups coded with random 3-digit numbers and a spoon was provided with each cup. For the ranking test, the portion size was $50 \mathrm{~g}$. Participants were instructed to collect a similar amount of product with the spoon $(\sim 15 \mathrm{~g})$ each time, and when particles were present, to make sure that both particles and quark were on the spoon, and to consume it as they would naturally. Data was collected using EyeQuestion ${ }^{\circledR}$ software (V3.8.13, Logic 8, The Netherlands).

\subsubsection{Data analysis}

IBM SPSS Statistics 25 (SPSS Inc., USA) was used to analyse the data. Analysis of Variance (ANOVA) was performed on the data obtained instrumentally (viscosity and penetration tests). Liking scores were analysed using ANOVA with sample as fixed factor and panellist as random factor, and Tukey's HSD ( $\mathrm{p}<0.05)$ was used as post-hoc test. Data obtained from the ranking test were initially analysed considering either rank positions (non-parametric test) or rank intensity scores (parametric test). Ranking positions for all attributes within each product set were analysed using a Friedman test and Wilcoxon signed rank test with Bonferroni adjustment. ANOVA was performed on the intensity scores obtained from the ranking on a line for each product set separately. Significant differences were further analysed using Tukey's HSD test $(\mathrm{p}<0.05)$ to specify the differences between samples. As both non-parametric and parametric analyses provided comparable outcomes and conclusions, only the rank intensity scores and related parametric analysis will be reported in the remainder of the manuscript.

\subsection{Temporal dominance of sensation (TDS)}

\subsubsection{Participants}

Fifty-one untrained participants $(n=51,38$ female, 13 male; average age: $21.6 \pm 2.1 \mathrm{yrs}$ ) were recruited for this test. None of the participants performing the TDS evaluation performed the ranking evaluation. The same selection criteria as for the ranking test applied (Section 2.4.1). Written informed consent was signed by all participants at the beginning of the sensory test.

\subsubsection{Method}

During one session of $30 \mathrm{~min}$, eight different quarks were tested (Table 1). As for the ranking test, homogeneous plain quark (LF) and quark containing microparticles ( $\mathrm{LF} \mid \mathrm{mp}$ ) were used as reference samples. The influence of macroparticle addition was investigated by adding soft and hard granola to low-fat quarks (LF $|\mathrm{mp}| \mathrm{SG}, \mathrm{LF}|\mathrm{mp}| \mathrm{HG}$ ), and soft and hard peach gel pieces added to low-fat quarks (LF $|\mathrm{mp}| \mathrm{SP}$, $\mathrm{LF}|\mathrm{mp}| \mathrm{HP}$ ). For samples containing macroparticles, low-fat quark was used to highlight the effect of macroparticle addition only on the perception of quarks, and not a combined effect of macroparticles and fat addition. The effect of fat concentration on dynamic perception of quarks was investigated by testing mid- and full-fat quark containing microparticles ( $\mathrm{MF}|\mathrm{mp}, \mathrm{FF}| \mathrm{mp}$ ). Before starting with the tasting session, 
participants received a short introduction on how to perform the TDS task and how to interpret the sensory attributes (Table 2). An extra practise sample (strawberry yoghurt mixed with cornflakes) was provided to the participants to get acquainted with the TDS task. The eight quarks were presented in a monadic counterbalanced sequence and the attributes order was randomized. Participants evaluated the samples over time as previously described (Lenfant, Loret, Pineau, Hartmann, \& Martin, 2009; Pineau et al., 2009). Researchers clarified that the selection of the attributes should be based on the concept of dominance, defined as the sensation that is catching their attention the most at a given time. It was explained that the dominant attribute is not necessarily the one with the highest intensity. For this task, one spoon of quark $(\sim 15 \mathrm{~g})$ was provided to the participants. The average consumption time of all samples during the TDS task was $12.6 \pm 2.5 \mathrm{~s}$. The sensory evaluation took place in the Consumer Research Room (Department of Social Sciences, Wageningen University). Participants were instructed to cleanse their palate with unsalted crackers and rinsing with water between the evaluation of each sample. EyeQuestion ${ }^{\circledR}$ software (V3.8.13, Logic 8, The Netherlands) was used for data collection. The sensory studies were performed in accordance with the Declaration of Helsinki.

\subsubsection{Data analysis}

TimeSens software (version 1.1.601.0, ChemoSens, Dijon, France) was used to process the TDS data. Dominance curves representing the proportion (\%) of participants who cited an attribute as dominant at that moment in time were obtained for each product as explained by Pineau et al. (2009).

\section{Results and discussion}

\subsection{Ranking test and hedonic evaluation}

\subsubsection{Effect of microparticles on sensory perception and liking of quark}

As expected, the addition of hard cellulose microparticles $(263 \mu \mathrm{m})$ to low-fat quark led to a significant decrease in perceived creaminess, while grittiness and dryness increased significantly in each of the product set tested (Tables 3-5).

The presence of microparticles in low-fat quark (LF $\mid \mathrm{mp}$ ) resulted in significantly lower overall and texture liking scores than for homogeneous low-fat quark (LF; Tables 3-5). We relate this decrease in liking to the relatively high grittiness and low creaminess perception of the quark with added microparticles in comparison to plain quark. No differences were observed in terms of flavour liking between LF and $\mathrm{LF} \mid \mathrm{mp}$ quarks. This is in line with our expectation as the added microparticles did not contain any flavour. In general, these results confirm that perception of hard, microscopic particles as gritty and dry sensations in a product that is expected to be homogeneous, reduces liking.

3.1.2. Effect of granola pieces on sensory perception and liking of quarks containing microparticles

Addition of granola pieces and microparticles to quark affected sensory perception of all attributes significantly (Table 3 ). The addition of hard granola (LF|HG) to homogeneous low-fat quark (LF) increased significantly sweetness, crunchiness, grittiness, hardness, and flavour intensity, while it decreased sourness and creaminess.

By comparing quarks containing microparticles (LF $|\mathrm{mp}, \mathrm{LF}| \mathrm{mp} \mid \mathrm{SG}$, $\mathrm{LF}|\mathrm{mp}| \mathrm{HG}$ ), we observe that the addition of granola pieces (soft/hard) also contributed significantly to lowering creaminess and sourness perception, whereas crunchiness and overall flavour intensity increased significantly (Table 3). However, no differences in grittiness were observed between quarks containing microparticles (LF $\mid \mathrm{mp}$ ) and the ones with granola (LF $|\mathrm{mp}| \mathrm{SG}, \mathrm{LF}|\mathrm{mp}| \mathrm{HG}$ ), suggesting that participants still perceived microparticles even when granola pieces were present. The granola was not able to change the detectability of the particles, and therefore the quarks were still perceived as gritty. However, considering that homogeneous quarks containing hard granola pieces (LF|HG) were perceived significantly grittier than the homogeneous quark (LF), we conclude that granola pieces also contributed to participants' grittiness perception. As the quarks with both microparticles and granola $(\mathrm{LF}|\mathrm{mp}| \mathrm{SG}, \mathrm{LF}|\mathrm{mp}| \mathrm{HG})$ are grittier than the quarks with only granola $(\mathrm{LF} \mid \mathrm{HG})$, grittiness scores are not dominated by the granola but are a cumulative effect of granola and microparticles.

As expected, quarks containing hard granola (LF $|\mathrm{mp}| \mathrm{HG}$ ) were perceived as significantly crunchier, harder, and with overall higher flavour intensity than quarks with added soft granola (LF $|\mathrm{mp}| \mathrm{SG}$ ). Variations in granola hardness, however, did not affect grittiness perception. We conclude that addition of granola pieces to quark containing microparticles can significantly boost positive sensory perceptions as sweetness, crunchiness and overall flavour intensity, but these positive perceptions do not influence the scores of the negative gritty sensations.

Incorporation of hard granola pieces to homogeneous quark (LF|HG, LF) provided significant higher scores for overall, texture, and flavour liking (Table 3). Such a positive effect of granola on hedonic responses was observed also for quarks containing microparticles (LF $|\mathrm{mp}| \mathrm{SG}$, $\mathrm{LF}|\mathrm{mp}| \mathrm{HG})$ as these were significantly more liked than quark containing microparticles only ( $\mathrm{LF} \mid \mathrm{mp})$ and even than the homogeneous quark (LF). Considering both ranking and liking outcomes, the results indicate that granola pieces can effectively improve participant hedonic responses of quark containing microparticles, although gritty sensations were still perceived by participants. We suggest that such an increase in liking of quarks with microparticles by the addition of granola pieces is caused by a possible shift in attention of participants to positive, more dominant sensations (i.e. crunchiness, sweetness, overall flavour

Table 3

Mean attribute rank intensity and liking scores ( \pm standard deviation) of the quarks belonging to the granola set. Different superscript letters across columns indicate significant differences among samples $(\mathrm{p}<0.05)$ per attribute obtained from Tukey's HSD.

\begin{tabular}{|c|c|c|c|c|c|}
\hline & LF & $\mathrm{LF} \mid \mathrm{mp}$ & $\mathrm{LF}|\mathrm{mp}| \mathrm{SG}$ & $\mathrm{LF}|\mathrm{mp}| \mathrm{HG}$ & $\mathrm{LF} \mid \mathrm{HG}$ \\
\hline \multicolumn{6}{|l|}{ Ranking scores } \\
\hline Sweet & $18 \pm 15^{\mathrm{a}}$ & $15 \pm 14^{\mathrm{a}}$ & $58 \pm 21^{b}$ & $61 \pm 19^{\mathrm{b}}$ & $57 \pm 23^{\mathrm{b}}$ \\
\hline Sour & $62 \pm 23^{\mathrm{b}}$ & $67 \pm 19^{b}$ & $34 \pm 19^{a}$ & $32 \pm 19^{a}$ & $38 \pm 23^{a}$ \\
\hline Creamy & $74 \pm 21^{d}$ & $58 \pm 26^{c}$ & $46 \pm 19^{a b}$ & $41 \pm 21^{a}$ & $49 \pm 22^{b}$ \\
\hline Crunchy & $6 \pm 6^{a}$ & $11 \pm 14^{\mathrm{a}}$ & $49 \pm 24^{\mathrm{b}}$ & $81 \pm 15^{\mathrm{d}}$ & $76 \pm 18^{c}$ \\
\hline Gritty & $11 \pm 16^{\mathrm{a}}$ & $54 \pm 30^{c}$ & $49 \pm 24^{c}$ & $53 \pm 26^{c}$ & $34 \pm 26^{b}$ \\
\hline Hard & $8 \pm 13^{a}$ & $11 \pm 13^{a}$ & $52 \pm 21^{b}$ & $62 \pm 20^{c}$ & $58 \pm 21^{c}$ \\
\hline Dry & $31 \pm 27^{\mathrm{a}}$ & $42 \pm 28^{\mathrm{b}}$ & $45 \pm 22^{b}$ & $44 \pm 24^{\mathrm{b}}$ & $44 \pm 23^{b}$ \\
\hline Flavour intensity & $35 \pm 25^{a}$ & $36 \pm 25^{a}$ & $50 \pm 22^{b}$ & $64 \pm 7^{c}$ & $63 \pm 18^{c}$ \\
\hline \multicolumn{6}{|l|}{ Liking scores } \\
\hline Overall liking & $5.7 \pm 1.7^{\mathrm{b}}$ & $4.5 \pm 1.6^{\mathrm{a}}$ & $5.4 \pm 1.7^{\mathrm{b}}$ & $6.9 \pm 1.4^{\mathrm{c}}$ & $6.8 \pm 1.3^{\mathrm{c}}$ \\
\hline Texture liking & $6.4 \pm 1.7^{\mathrm{b}}$ & $4.3 \pm 1.8^{\mathrm{a}}$ & $5.3 \pm 2.1^{\mathrm{a}}$ & $6.8 \pm 1.6^{b c}$ & $6.5 \pm 1.9^{c}$ \\
\hline Flavour liking & $5.3 \pm 1.7^{\mathrm{a}}$ & $4.8 \pm 1.7^{\mathrm{a}}$ & $6.4 \pm 1.4^{\mathrm{b}}$ & $6.7 \pm 1.4^{\mathrm{c}}$ & $6.3 \pm 1.7^{b c}$ \\
\hline
\end{tabular}


Table 4

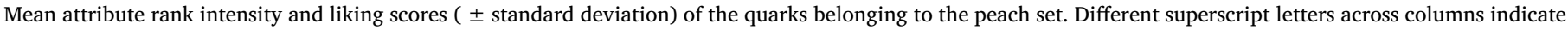
significant differences among samples $(\mathrm{p}<0.05)$ per attribute obtained from Tukey's HSD.

\begin{tabular}{|c|c|c|c|c|c|}
\hline & LF & $\mathrm{LF} \mid \mathrm{mp}$ & $\mathrm{LF}|\mathrm{mp}| \mathrm{SP}$ & $\mathrm{LF}|\mathrm{mp}| \mathrm{HP}$ & $\mathrm{LF} \mid \mathrm{SP}$ \\
\hline \multicolumn{6}{|l|}{ Ranking scores } \\
\hline Sweet & $18 \pm 14^{\mathrm{a}}$ & $18 \pm 14^{\mathrm{a}}$ & $53 \pm 21^{c}$ & $43 \pm 19^{b}$ & $53 \pm 21^{c}$ \\
\hline Sour & $58 \pm 21^{\mathrm{b}}$ & $63 \pm 21^{\mathrm{b}}$ & $37 \pm 18^{a}$ & $42 \pm 19^{a}$ & $35 \pm 20^{a}$ \\
\hline Creamy & $71 \pm 23^{c}$ & $50 \pm 25^{a}$ & $43 \pm 21^{a}$ & $43 \pm 21^{a}$ & $62 \pm 20^{\mathrm{b}}$ \\
\hline Crunchy & $8 \pm 12^{a}$ & $19 \pm 20^{\mathrm{b}}$ & $36 \pm 23^{d}$ & $42 \pm 26^{\mathrm{d}}$ & $28 \pm 21^{c}$ \\
\hline Gritty & $12 \pm 17^{\mathrm{a}}$ & $63 \pm 25^{\mathrm{b}}$ & $57 \pm 25^{b}$ & $57 \pm 24^{\mathrm{b}}$ & $18 \pm 18^{a}$ \\
\hline Hard & $10 \pm 15^{a}$ & $20 \pm 20^{b}$ & $36 \pm 20^{c}$ & $50 \pm 26^{d}$ & $29 \pm 21^{c}$ \\
\hline Dry & $32 \pm 25^{\mathrm{ab}}$ & $44 \pm 27^{c}$ & $36 \pm 24 b c$ & $40 \pm 26^{b c}$ & $24 \pm 18^{a}$ \\
\hline Flavour intensity & $39 \pm 28^{a}$ & $36 \pm 25^{\mathrm{a}}$ & $51 \pm 20^{\mathrm{b}}$ & $49 \pm 21^{\mathrm{b}}$ & $54 \pm 22^{\mathrm{b}}$ \\
\hline \multicolumn{6}{|l|}{ Liking scores } \\
\hline Overall liking & $5.7 \pm 1.7^{\mathrm{c}}$ & $4.5 \pm 1.6^{\mathrm{a}}$ & $4.9 \pm 1.7^{\mathrm{ab}}$ & $4.3 \pm 1.6^{\mathrm{a}}$ & $5.4 \pm 1.6^{b c}$ \\
\hline Texture liking & $6.4 \pm 1.7^{\mathrm{c}}$ & $4.3 \pm 1.8^{\mathrm{a}}$ & $4.4 \pm 2.0^{\mathrm{a}}$ & $4.2 \pm 1.7^{\mathrm{a}}$ & $5.3 \pm 1.8^{\mathrm{b}}$ \\
\hline Flavour liking & $5.3 \pm 1.7^{\mathrm{a}}$ & $4.8 \pm 1.7^{\mathrm{a}}$ & $5.2 \pm 1.6^{\mathrm{a}}$ & $4.9 \pm 1.6^{\mathrm{a}}$ & $5.4 \pm 1.7^{\mathrm{a}}$ \\
\hline
\end{tabular}

intensity). This will be discussed further in Section 3.2. This effect was larger for quark containing hard granola pieces (LF $|\mathrm{mp}| \mathrm{HG}$ ) than for quark containing soft granola pieces (LF $|\mathrm{mp}| \mathrm{SG}$ ), probably because participants preferred products with crunchy pieces over quark containing soft granola pieces. We conclude that addition of granola pieces to quark can not only prevent a decrease in liking when microparticles are present, but can even increase liking of a quark with microparticles in comparison to the respective homogeneous version.

\subsubsection{Effect of peach gel pieces on sensory perception and liking of quark containing microparticles}

All quark sensory attributes were found to be significantly affected by the addition of microparticles and/or peach gel pieces (Table 4). Quark containing soft peach gel pieces (LF|SP) were perceived significantly sweeter, crunchier, harder and with a higher flavour intensity than homogeneous low-fat quark (LF). Similar to the effects observed for quark containing hard granola, the addition of soft peach gel pieces to homogeneous quark decreased sourness and creaminess significantly. Quarks containing microparticles (LF $|\mathrm{mp}, \mathrm{LF}| \mathrm{mp}|\mathrm{SP}, \mathrm{LF}| \mathrm{mp} \mid \mathrm{HP}$ ) scored equally in grittiness and creaminess, signifying that addition of peach gel pieces (soft/hard) did not prevent microparticle detection, and accompanying gritty sensations. The presence of peach gel pieces in quark with microparticles led to higher crunchiness, hardness, and overall flavour intensity perception than in quarks containing only microparticles (LF $\mid \mathrm{mp}$ ). Variations in mechanical properties between soft and hard peach gel pieces resulted only in a higher sweetness when the particles were soft and higher hardness when the particles were hard. We conclude that incorporation of peach gel pieces to quark containing undesired microparticles cannot prevent negative gritty sensations or decrease in perceived creaminess, although their addition can boost positive sensory perception, such as sweetness, crunchiness, and overall flavour intensity.

The addition of soft peach gel pieces to low-fat quark (LF|SP, LF) did not result in a change in overall liking scores, but decreased texture liking significantly (Table 4). When comparing the overall liking and texture liking scores of quarks containing microparticles (LF $\mid \mathrm{mp}$ ) with those with added peach gel pieces (LF $|\mathrm{mp}| \mathrm{SP}, \mathrm{LF}|\mathrm{mp}| \mathrm{HP}$ ), no significant differences were observed. Addition of peach gel pieces did not prevent a decrease in hedonic responses caused by microparticle addition. This is probably related to the fact that the peach gel pieces were themselves not very well liked, possibly as a result of disconfirmation of expectations due to the unfamiliar texture of the gel (Santagiuliana, van den Hoek et al., 2019). The variation in their hardness did not affect liking scores. In contrast to the addition of fat and granola, the positive sensations (e.g. sweetness and flavour intensity) induced by addition of peach gel pieces did not inhibit the decline in product liking of quarks with microparticles. We conclude that a possible hedonic compensation or shift in participants' attention towards positive sensations in quark containing microparticles depends on the properties of the added macroparticles and their ability to positively contribute to liking.

\subsubsection{Effect of fat on sensory perception and liking of quarks containing microparticles}

Sensory perception of quark differed considerably between samples varying in fat content as significant differences were found between samples for all attributes (Table 5). Considering the similarity in composition reported in Section 2.1, we expected that these changes were primarily related to differences in fat content. However, we cannot exclude that small differences in the composition or production process might have been present between the two commercially available LF and FF quark.

An increase in fat content from 0 to $8.8 \%$ (LF, FF) in homogeneous

Table 5

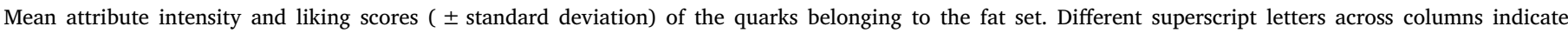

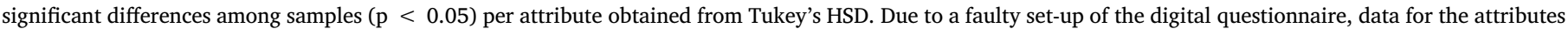
dryness and flavour intensity were not recorded.

\begin{tabular}{|c|c|c|c|c|c|}
\hline & LF & $\mathrm{LF} \mid \mathrm{mp}$ & $\mathrm{MF} \mid \mathrm{mp}$ & $\mathrm{FF} \mid \mathrm{mp}$ & $\mathrm{FF}$ \\
\hline \multicolumn{6}{|l|}{ Intensity scores } \\
\hline Sweet & $22 \pm 20^{a}$ & $20 \pm 19^{a}$ & $35 \pm 19^{b}$ & $43 \pm 22^{c}$ & $47 \pm 25^{c}$ \\
\hline Sour & $62 \pm 23^{c}$ & $64 \pm 22^{c}$ & $47 \pm 22^{b}$ & $31 \pm 20^{\mathrm{a}}$ & $29 \pm 23^{a}$ \\
\hline Creamy & $67 \pm 22^{b}$ & $50 \pm 25^{a}$ & $49 \pm 24^{\mathrm{a}}$ & $49 \pm 24^{\mathrm{a}}$ & $55 \pm 26^{\mathrm{b}}$ \\
\hline Crunchy & $13 \pm 17^{\mathrm{a}}$ & $31 \pm 27^{\mathrm{b}}$ & $30 \pm 26^{\mathrm{b}}$ & $25 \pm 24^{\mathrm{b}}$ & $8 \pm 10^{a}$ \\
\hline Gritty & $14 \pm 13^{a}$ & $63 \pm 23^{b}$ & $57 \pm 25^{b}$ & $55 \pm 27^{b}$ & $8 \pm 12^{a}$ \\
\hline Hard & $17 \pm 20^{\mathrm{b}}$ & $30 \pm 24^{\mathrm{d}}$ & $26 \pm 22^{\mathrm{cd}}$ & $22 \pm 21^{b c}$ & $7 \pm 8^{a}$ \\
\hline \multicolumn{6}{|l|}{ Liking scores } \\
\hline Overall liking & $5.7 \pm 1.7^{\mathrm{c}}$ & $4.5 \pm 1.6^{\mathrm{a}}$ & $5.3 \pm 1.8^{b c}$ & $5.0 \pm 2.0^{\mathrm{ab}}$ & $6.4 \pm 1.6^{\mathrm{d}}$ \\
\hline Texture liking & $6.4 \pm 1.7^{c}$ & $4.3 \pm 1.8^{\mathrm{a}}$ & $4.9 \pm 2.1^{\mathrm{b}}$ & $5.6 \pm 2.1^{\mathrm{ab}}$ & $6.9 \pm 1.3^{\mathrm{c}}$ \\
\hline Flavour liking & $5.3 \pm 1.7^{\mathrm{ab}}$ & $4.8 \pm 1.7^{\mathrm{a}}$ & $5.5 \pm 2.1^{b c}$ & $5.6 \pm 2.1^{\mathrm{ab}}$ & $6.3 \pm 1.7^{\mathrm{c}}$ \\
\hline
\end{tabular}


quarks significantly increased sweetness, whereas sourness and hardness decreased. These effects were also observed when quarks differing in fat content containing microparticles were compared $(\mathrm{LF} \mid \mathrm{mp}$, $\mathrm{MF}|\mathrm{mp}, \mathrm{FF}| \mathrm{mp}$ ), suggesting that the presence of fat in quark can significantly influence perceived sweetness, sourness, and hardness even when microparticles are present and perceived. Conversely, the results show that fat addition had no significant effect on perceived grittiness, creaminess, and crunchiness for quark containing microparticles.

The results indicate that creaminess did not significantly differ between low-fat quark (LF) with a score of 66 and full-fat quark (FF) with a score of 55. This was not expected as full-fat quark should be perceived considerably creamier than low-fat quark due to the lubrication abilities of the dispersed fat droplets. Potential reasons could be related to the properties of the continuous protein phase (i.e. fine vs course protein network) or a different production process (e.g. homogenization) between the two commercial quark types. The low-fat quark has apparently been successfully modified in such a way that the creaminess is the same as the one of the full-fat quark. Therefore, although the results showed that higher fat content in quark containing microparticles did not reduce grittiness (Table 5), we cannot yet conclude from this study that lubrication cannot be used as an effective strategy to reduce detectability of microparticles $(>200 \mu \mathrm{m}$ ) and therefore reduce perceived gritty sensations. To verify such strategy, quarks with the same properties in the continuous phase and an obvious effect of fat addition on the attribute creaminess would be required.

An increase in fat content from 0 to $8.8 \%$ in homogeneous quarks (LF, FF) provided a significant increase in overall liking and flavour liking, but no differences were observed between the two samples in terms of texture liking (Table 5). With the addition of microparticles, significant lower overall and texture liking scores were recorded for all quarks (LF $|\mathrm{mp}, \mathrm{MF}| \mathrm{mp}, \mathrm{FF} \mid \mathrm{mp}$ ) regardless of the fat content. This shows that quarks with microparticles were less liked than the respective smooth products. Quark with mid-fat content and microparticles (MF $\mid \mathrm{mp}$ ) were significantly more liked than quark with microparticles and no fat (LF|mp). Therefore, it seems that fat can increase liking of the product, although the particles could still be perceived. However, when the fat content was increased further (FF $\mid \mathrm{mp}$ ), no further increase in overall liking was observed, and no differences between mid-fat $(\mathrm{MF} \mid \mathrm{mp})$ and full-fat $(\mathrm{FF} \mid \mathrm{mp})$ quarks containing microparticles were shown. Although fat seems to increase liking, the quarks with microparticles and fat are still much less liked than quarks without microparticles. As no differences were observed in grittiness between quarks with microparticles varying in fat content, we relate the increased liking of quarks with fat more to their higher ratings in sweetness and lower sourness (Table 5) than to differences in creaminess. We conclude that although the presence of fat in quark did not decrease perception of grittiness, it marginally positively affects the liking scores of quark.

\subsection{TDS}

\subsubsection{Effect of addition of microparticles on dynamic sensory perception of} quarks

To further investigate the perception of homogeneous and heterogeneous quarks and to identify possible explanations for the hedonic responses previously reported, Temporal Dominance of Sensations (TDS) was used. Fig. 1A and B show the temporal profiles of participants $(n=51)$ for low-fat quarks without and with microparticles, respectively. The dynamic profile of homogeneous quarks was characterized by an alternate dominance of the attributes creaminess, dairy flavour, and sourness. Dryness dominance increased towards the end of consumption without reaching significance level, whereas the remaining attributes did not overcome chance level. Upon addition of microparticles (Fig. 1B), creaminess remained the most dominant attribute, but grittiness dominance rates also presented high values at the beginning of consumption. Grittiness dominance decreased progressively reaching non-significance level at approximately onethird of the total time. Such a high dominance rate of gritty sensations over time led to overall lower dominance rates of dairy flavour and sourness in the first half of consumption time in comparison to homogeneous quark. The presence of microparticles also increased dominance of dryness, which became significant at the end of consumption. Therefore, microparticle addition mainly determined modifications of the dynamic sensory profile of quarks during the first and last part of sensory evaluation.

In conclusion, presence of microparticles in quark increases dominance of gritty and dry sensations at the beginning and end of consumption, while dominance of flavour attributes (i.e. sourness and dairy flavour) in the first part of oral manipulation is reduced.

\subsubsection{Effect of granola pieces on dynamic sensory perception of quarks containing microparticles}

The effect of granola pieces added to quarks containing microparticles is shown in Fig. 1C and D. As observed in the ranking outcomes (Table 3), the incorporation of granola pieces (soft/hard) strongly changed the perceived product profile of quarks with a shift from quark-related to granola-related dominant attributes. For quarks containing soft granola pieces (Fig. 1C), the first half of the dynamic sensory profile was characterized by creamy and hard sensations, leading to progressively higher dominance of sweet and wheat-flavour perception. For this type of granola, crunchiness was not perceived as a dominant sensation. For quarks containing hard granola pieces (Fig. 1D), the first two-thirds of consumption was dominated by crunchiness perception followed by wheat and sweet sensations. The increase in hardness of the granola induced a shift from hard to crunchy. As a consequence of these dominant perceptions, hard and crunchy, lower dominance rates of sourness and dairy flavour were observed in quarks containing either of the granola types. Similarly, grittiness perception never reached significance level for both products, supporting the hypothesis that the positive, more dominant sensations have caused a shift in attention of participants away from unpleasant perception, such as grittiness. This positive effect of added granola on dynamic sensory profile was also observed as the dominance ratings for dryness decreased, which did not reach significance level at the end of consumption. We conclude that addition of granola pieces provides dominant positive perception (i.e. crunchiness) to quarks, which can effectively compensate for the undesired gritty, sour, and dry sensations. In addition, the granola pieces may also direct away the participants' attention from the undesired sensations.

\subsubsection{Effect of peach gel pieces addition on dynamic sensory perception of} quarks containing microparticles

The temporal profiles of quarks containing peach gel pieces and microparticles are illustrated in Fig. $1 \mathrm{E}$ and F. The results show that addition of peach gel pieces to quarks containing microparticles determined significant changes especially in the second part of the product oral consumption. For both quarks containing soft and hard peach gel pieces, the dominance of dairy flavour observed for quark containing microparticles (Fig. 1B) was replaced by relatively high dominance rates of peach flavour. For both peach types, creamy and sour perception dominated the first half of product evaluation. Soft peach gel pieces were more effective in preventing dominance of grittiness and dryness than the respective hard version as the dominance rate for these attributes progressively increased, reaching significance level in the second half of consumption when hard peach gel pieces were present. These results indicate that optimization of dynamic sensory perception of quarks containing microparticles depends on the properties (i.e. hardness) of added peach gel pieces. The low dominance of grittiness, however, did not improve liking for quarks containing microparticles and peach gel pieces (Table 4). We conclude that a shift in participants' attention away from gritty sensations might not have been large enough for such relatively soft macroparticles (approx. 35-100 

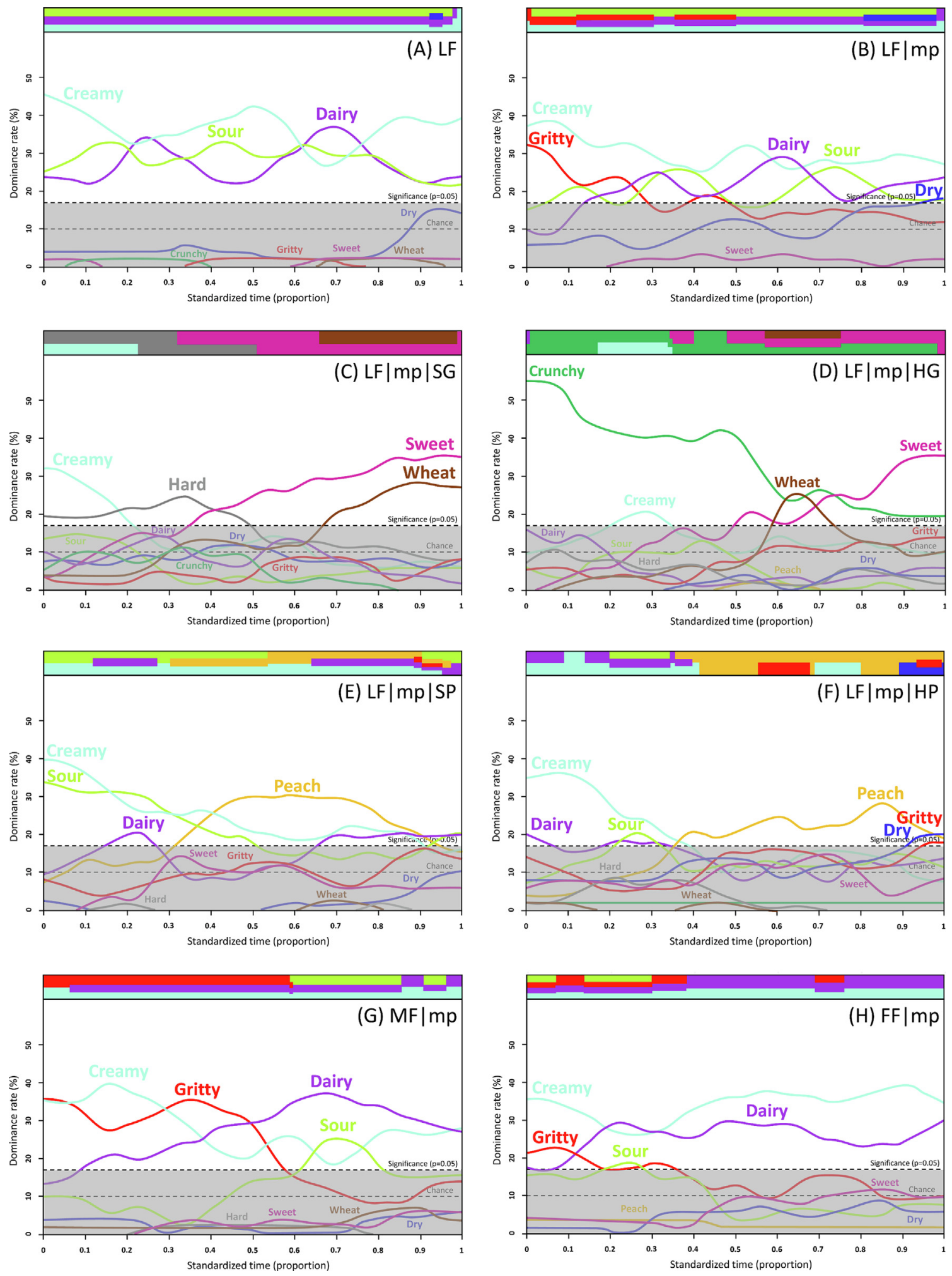

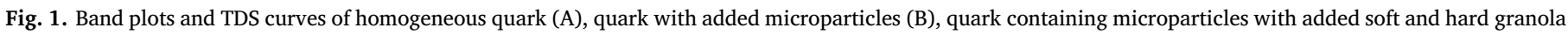

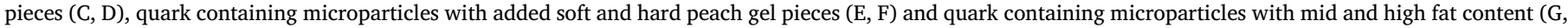
$\mathrm{H}$ ) over standardized eating time. The abbreviations are explained in Table 1.

times softer than the granola) or, alternatively, that the change in attention might not be the only mechanism able to explain the differences in dominance rates observed upon addition of other macroparticles.
3.2.4. Effect of fat addition on dynamic sensory perception of quarks containing microparticles

Variations in fat content caused significant modifications in dynamic sensory perception in quarks containing microparticles (Fig. 1G and $\mathrm{H}$ ). When $4.4 \%$ fat was added to quark containing microparticles (Fig. 1G), the temporal perception was largely dominated by creamy 
and gritty sensations during the first half of consumption time. For this product, dairy flavour and sourness dominance rates increased progressively over time, reaching their maximum value towards threefourths of total oral evaluation time. A further increase in fat content to $8.8 \%$ (Fig. 1H) resulted in an increase of creaminess dominance throughout the entire sample evaluation, while grittiness and sourness dominance decreased considerably in comparison with the mid-fat quark with added microparticles. For both $\mathrm{MF} \mid \mathrm{mp}$ ( $4.4 \%$ fat) and $\mathrm{FF} \mid \mathrm{mp}(8.8 \%$ fat) quarks, dryness dominance did not reach significance level, indicating that presence of fat at both 4.4 and $8.8 \%$ in quark can reduce the dominance of such a negative sensation.

When comparing the dynamic perception with the static scores obtained during the ranking test, both similarities and differences can be observed across quarks with different fat content. For instance, the progressively lower sourness sensation observed during dynamic evaluation for the mid-fat and full-fat quark is in agreement with the results of the static evaluation in which fat-containing quarks presented significantly lower scores than the low-fat quark containing microparticles. Conversely, when microparticles were present, the ranking outcomes did not highlight any significant difference in the effect on creaminess and grittiness of the quark containing a high fat content (8.8\%; $\mathrm{FF} \mid \mathrm{mp})$ in comparison to the scores for quark with a lower fat content $(4.4 \%$; $\mathrm{MF} \mid \mathrm{mp})$. This could possibly suggest that the presence of fat in quark did play a minor role in perception of creamy and gritty sensations over time, although such effects could not be observed in the static evaluation by the ranking test.

When the dynamic sensory profiles of quarks with added microparticles varying in fat content are compared to low-fat quarks containing microparticles (Fig. 1B, G, H), it can be seen that grittiness dominance rates were considerably higher in quarks containing $4.4 \%$ fat than in low-fat and full-fat quarks. We explain this non-linear effect of fat addition on dominance of grittiness by the fact that the present fat not only affects the attribute creaminess, but also modifies the matrix sensory profile with respect to attributes as sourness and dryness. For sample $L F \mid m p$, the perception of multiple negative sensations as high grittiness, high sourness, and high dryness determined an increased difficulty for the participants to determine the most dominant attribute during the first part of consumption. As a result, there was little consensus between the participants, and scores did not reach significant levels. Conversely, for sample MF|mp, apparently the lower sourness and expected lower dryness did not draw the attention as a negative attribute (Table 3), and therefore grittiness was perceived dominant by many participants. Finally, for sample FF $\mid \mathrm{mp}$, the even lower sourness and dryness as a negative contribution in combination with a possible positive effect of the lubrication properties of fat resulted in a low dominance of gritty sensations over time. We conclude that high fat content in quark can decrease dominance of negative sensations as grittiness and sourness over time, while it increases positive dominance sensations as creaminess.

\subsection{General discussion}

This study aimed to examine whether the addition of macroparticles or fat to quark can be used to perceptually compensate for undesired gritty sensations caused by hard microparticles. None of the tested strategies allowed to decrease gritty sensations, and therefore were not able to mask grittiness. Nonetheless, addition of fat or granola pieces to quarks containing microscopic cellulose beads increased liking. So even though grittiness was still perceived, the different strategies affected perception and appreciation. We suggest that the observed effects might be caused by (i) a shift in participants' attention induced by perceptions of more dominant sensations (cognitive attention-driven mechanism), and (ii) compensation of the gritty negative perceptions by more positive ones (hedonic compensation effect).

The attention-driven mechanism might be supported by the findings obtained during the dynamic sensory evaluation of quark as the presence of macroparticles increased the dominance rate of macroparticle related positive sensations (crunchiness) and suppressed dominance of microparticle related negative sensations (grittiness). Such an effect was also observed when in an additional, explorative study (data not shown) other macroparticles (i.e. chocolate chunks, canned peach cubes) were used and evaluated for their sensory profile and liking. For instance, when chocolate chunks were added to quark containing microparticles, the high dominance of perceived crunchiness and chocolate flavour led to suppression of the dominance of gritty sensations, so it may have shifted attention away from these negative sensations. This suggests that the dominance of sensations in foods can be influenced by a combination of different components providing contrasting texture and flavours and this is in line with previous work on heterogeneous products (Tang et al., 2017). It also suggests that a variety of macroparticles such as granola, chocolate chunks and canned peach cubes can be used to direct attention and possibly to increase liking of foods with undesired texture sensations.

The addition of granola pieces was demonstrated to be the most effective strategy to prevent a decrease in liking of quarks with added microparticles, while addition of peach gel pieces showed to be considerably less effective in such a task. Both macroparticles (peach and granola) provided positive and more dominant sensations during consumption and, therefore, we suggest that participants' expectations might have also played a role during the evaluation of quarks as the importance of expectations on product acceptance is already known (Costell, Tárrega, \& Bayarri, 2010; Deliza, 1995; Deliza \& Macfie, 1996; Higgs, 2015; Tarancón, Sanz, Fiszman, \& Tárrega, 2014). We hypothesize that during the chewing process of granola pieces, the participants expect the formation and presence of particles of different sizes as a result of product breakdown and related reduction in size of the macroparticles. On the contrary, participants do not expect the perception of small gritty particles as a result of oral breakdown of peach gel pieces. Consequently, the type of stimulus triggered by the presence of microparticles in the two products did not change, but participants textural expectations did. This suggests that to efficiently compensate for undesired textural sensations caused by microparticles, the selection of the type of macroparticles should be based on the presence of attributes that are relatively similar to those of the microparticles. We conclude that the recognition of the origin of gritty sensations (i.e. from which food component the microparticles originate) in a product is a crucial factor in determining participants' hedonic response.

However, the attention-driven mechanism is not sufficient to explain differences in liking between the different quarks with added granola, peach gel pieces, or fat. For instance, the TDS outcomes highlighted that mid-fat quarks with particles (MF $\mid \mathrm{mp}$ ) presented higher rates of grittiness dominance over time than the respective lowfat quarks (LF $\mid \mathrm{mp}$ ), although the mid-fat gritty quarks were more liked. For such fat-containing samples, modifications of other sensations besides grittiness can also contribute to an effective hedonic compensation of the negative perceptions. For example, a reduction of product sourness or increase in sweetness might help the participants to compensate for the negative sensations of grittiness. To test this, we performed additional, exploratory tests (data not shown) by adding sugar $(2.3 \% \mathrm{w} / \mathrm{w})$ to quark containing microparticles and evaluated the dynamic perception and liking. Dominance of sweet sensations was increased, while sourness dominance was reduced. Although addition of sugar did not decrease grittiness dominance, liking of the sweetened quark was higher than the respective unsweetened quark. This confirms indeed that positive sensations (i.e. sweetness) can determine an effective hedonic compensation of the negative gritty sensations.

The hedonic compensation effect can also be explained by the intrinsic palatability of the particles. In fact, considering the hedonic scores of the quark without microparticles, the presence of hard granola pieces provided the largest increase in overall liking $(+1.1$ based on average score), followed by full-fat quark $(+0.7$ based on average 
score), while no differences were found for quark with added soft peach gel pieces (LF $\mid S P)$. These results coincide with the effectiveness of the tested strategies and we therefore suggest that liking of added particles itself is a critical factor that determines the hedonic compensation of negative sensations. Further investigation is required to establish which psychological mechanisms (either perception-driven or liking-driven or a combination of the two) is mainly responsible for the perceptual compensation effect of microparticles.

The present findings have significant implications for the design of both pharmaceutical delivery systems and food products. Patient rejection of particulate formulations could be limited or prevented if the drug carriers are provided in a food matrix in combination with other macroparticles (e.g. combining multiparticulate formulations with granola pieces that can be added to different dairy products). From a food development perspective, addition of macroparticles providing positive sensory sensations into a food product can possibly counteract negative product textural defects, so the strategy could be used to compensate for undesired texture sensations in foods. Gritty, rough and dry feelings originated from presence of protein aggregates in proteinenriched liquid foods, or fibres in foods could be mitigated by such textural combination. For instance, addition of particles (e.g. addition of coconut flakes, chocolate sprinkles, or granola pieces to quark/yoghurt) could allow better acceptability of products containing microparticles, such as high-protein dairy products.

\section{Conclusions}

This study aimed to investigate whether the addition of macroparticles or fat to quark could be used to perceptually compensate for negative gritty sensations caused by microparticles. The addition of granola pieces to quark containing microparticles prevented the decrease in liking, even though grittiness was still perceived. So grittiness was not masked by any of the strategies, but addition of macroparticles or fat was able to compensate for the negative sensations. The TDS profiles of quarks containing microparticles indicated that the presence of granola pieces changed the focus of attention of participants towards more positive and dominant sensations (i.e. crunchiness), preventing a decrease in hedonic responses. Conversely, the incorporation of peach gel pieces to quark containing microparticles did not prevent gritty sensations nor avoid a decline in liking. We related the different effects of the two macroparticles on liking of quarks with gritty sensations to the different expectations of the consumers, as participants did not expect the presence of small hard particles when peach gel pieces were present, whereas the presence of small particles is not uncommon for granola. This suggested that participants' expectations determine the interpretation of the stimulus triggered by the presence of microparticles and its effect on the product hedonic response. When a medium amount of fat was added (4.4\%), liking did not decrease, which is probably due to an effective hedonic compensation triggered by more positive sensations (i.e. sweetness). Higher level of fat (8.8\%) in quark did not significantly improve liking nor reduced perceived grittiness. Overall, these results show that incorporation of well-liked macroparticles (i.e. crunchy granola pieces) or fat can be used as strategies to shift consumers' attention towards positive sensations leading to an increase of liking while negative sensations (grittiness) caused by structural heterogeneities (cellulose beads) are still sensed. These findings could help to prevent patient rejection of particulate formulations and food companies to optimize food products presenting textural defects.

\section{Acknowledgement}

The authors would like to thank Dimosthenis Ketigenidis and Resa Drost for helping in the execution of the TDS experiments.

\section{Competing interest}

The authors have declared that no competing interests exist.

\section{Funding source}

The research forms part of a project that is organised by TiFN, a public-private partnership on precompetitive research in food and nutrition, and executed under its auspices. The public partners are responsible for the study design, data collection and analysis, decision to publish, and preparation of the manuscript. The private partners FrieslandCampina, Fromageries Bel and Unilever have contributed to the project through regular discussions. Co-funding for the project was obtained from the Top-Consortium for Knowledge and Innovation Agri \&Food and the Netherlands Organisation for Scientific Research.

\section{References}

Chojnicka-Paszun, A., Doussinault, S., \& De Jongh, H. H. J. (2014). Sensorial analysis of polysaccharide-gelled protein particle dispersions in relation to lubrication and viscosity properties. Food Research International, 56, 199-210.

Costell, E., Tárrega, A., \& Bayarri, S. (2010). Food acceptance: The role of consumer perception and attitudes. Chemosensory Perception, 3(1), 42-50.

de Wijk, R. A., \& Prinz, J. F. (2005). The role of friction in perceived oral texture. Food Quality and Preference, 16(2), 121-129.

Deliza, R. (1995). External cues and its effect on sensory perception and hedonic ratings: A review. Journal of Sensory Studies, 11, 103-128.

Deliza, R., \& Macfie, H. J. H. (1996). The generation of sensory expectation by external cues and its effect on sensory perception and hedonic ratings: A review. Journal of Sensory Studies, 11(2), 103-128.

Devezeaux de Lavergne, M., Tournier, C., Bertrand, D., Salles, C., van de Velde, F., \& Stieger, M. (2015). Dynamic texture perception, oral processing behaviour and bolus properties of emulsion-filled gels with and without contrasting mechanical properties. Food Hydrocolloids, 52, 648-660.

Engelen, L., De Wijk, R. A., Van Der Bilt, A., Prinz, J. F., Janssen, A. M., \& Bosman, F. (2005). Relating particles and texture perception. Physiology and Behavior, 86(1-2), 111-117.

Engelen, L., Van Der Bilt, A., Schipper, M., \& Bosman, F. (2005). Oral size perception of particles: Effect of size, type, viscosity and method. Journal of Texture Studies, 36(4), $373-386$.

Higgs, S. (2015). Cognitive processing of food rewards. Appetite, 104, 10-17.

Hyde, J. R., \& Witherly, A. S. (1993). Dynamic contrast a sensory contribution to palatability. Appetite, 21, 1-16.

James, B. (2018). Oral processing and texture perception influences satiation. Physiology and Behavior, 193(2017), 238-241.

Kim, E. H. J., Jakobsen, V. B., Wilson, A. J., Waters, I. R., Motoi, L., Hedderley, D. I., \& Morgenstern, M. P. (2015). Oral processing of mixtures of food particles. Journal of Texture Studies, 487-498.

Kim, K.-O., \& O'Mahony, M. (1997). A new approach to category scales of intensity I: Traditional versus rank-rating. Journal of Sensory Studies, 13(530), 241-249.

Krzeminski, A., Tomaschunas, M., Köhn, E., Busch-Stockfisch, M., Weiss, J., \& Hinrichs, J. (2013). Relating creamy perception of whey protein enriched yogurt systems to instrumental data by means of multivariate data analysis. Journal of Food Science, 78(2), 314-319.

Larsen, D. S., Tang, J., Ferguson, L., Morgenstern, M. P., \& James, B. J. (2016). Oral breakdown of texturally complex gel-based model food. Journal of Texture Studies, 47(3), 169-180.

Lenfant, F., Loret, C., Pineau, N., Hartmann, C., \& Martin, N. (2009). Perception of oral food breakdown. The concept of sensory trajectory. Appetite, 52(3), 659-667.

Liu, K., Stieger, M., van der Linden, E., \& van de Velde, F. (2016). Effect of microparticulated whey protein on sensory properties of liquid and semi-solid model foods. Food Hydrocolloids, 60, 186-198.

Lopez, F. L., Bowles, A., Gul, M. O., Clapham, D., Ernest, T. B., \& Tuleu, C. (2016). Effect of formulation variables on oral grittiness and preferences of multiparticulate formulations in adult volunteers. European Journal of Pharmaceutical Sciences, 92, $156-162$.

Lopez, F. L., Mistry, P., Batchelor, H. K., Bennett, J., Coupe, A., Ernest, T. B., ... Tuleu, C. (2018). Acceptability of placebo multiparticulate formulations in children and adults. Scientific Reports, 1-10.

Marconati, M., Lopez, F., Tuleu, C., Orlu, M., \& Ramaioli, M. (2019). In vitro and sensory tests to design easy-to-swallow multi-particulate formulations. European Journal of Pharmaceutical Sciences, 132(30), 157-162.

Modler, H. W., Yiu, S. H., Bollinger, U. K., \& Kalab, M. (1989). Grittiness in a pasteurized cheese spread: A microscopic study. Food Microstructure, 8(2), 201-210.

Petersson, K., Eliasson, A. C., Tornberg, E., \& Bergenståhl, B. (2013). Sensory perception of rye bran particles of varying size and concentration in a viscous phase. Journal of Texture Studies, 44(6), 459-467.

Pineau, N., Schlich, P., Cordelle, S., Mathonnière, C., Issanchou, S., Imbert, A., ... Köster, E. (2009). Temporal dominance of sensations: construction of the TDS curves and comparison with time-intensity. Food Quality and Preference, 20(6), 450-455. 
Rohart, A., Sieffermann, J. M., \& Michon, C. (2015). Effect of micro-gel shape and concentration on sensory perception of micro-gels-enriched stirred yoghurts. Colloids and Surfaces A: Physicochemical and Engineering Aspects, 475(1), 94-102.

Sainani, M. R., Vyas, H. K., \& Tong, P. S. (2004). Characterization of particles in cream cheese. Journal of Dairy Science, 87(9), 2854-2863.

Santagiuliana, M., Bhaskaran, V., Scholten, E., Piqueras-Fiszman, B., \& Stieger, M. (2019). Don't judge new foods by their appearance! How visual and oral sensory cues affect sensory perception and liking of novel, heterogeneous foods. Food Quality and Preference, 77, 64-77.

Santagiuliana, M., Christaki, M., Piqueras-Fiszman, B., Scholten, E., \& Stieger, M. (2018). Effect of mechanical contrast on sensory perception of heterogeneous liquid and semi-solid foods. Food Hydrocolloids, 83, 202-212.

Santagiuliana, M., Marigómez, I. S., Broers, L., Hayes, J. E., Piqueras-Fiszman, B., Scholten, E., \& Stieger, M. (2019). Exploring variability in detection thresholds of microparticles through participant characteristics. Food \& Function, 15-19.

Santagiuliana, M., Piqueras-Fiszman, B., van der Linden, E., Stieger, M., \& Scholten, E. (2018). Mechanical properties affect detectability of perceived texture contrast in heterogeneous food gels. Food Hydrocolloids, 80, 254-263.

Santagiuliana, M., van den Hoek, I. A. F., Stieger, M., Scholten, E., \& Piqueras-Fiszman, B. (2019). As good as expected? How consumer expectations and addition of vegetable pieces to soups influence sensory perception and liking. Food \& Function, 10,
$665-680$.

Szczesniak, A. S., \& Kahn, E. L. (1984). Texture contrasts and combinations - A valued consumer attribute. Journal of Texture Studies, 15(3), 285-301.

Tang, J., Larsen, D. S., Ferguson, L., \& James, B. J. (2017). Textural complexity model foods assessed with instrumental and sensory measurements. Journal of Texture Studies, 48(1), 9-22.

Tarancón, P., Sanz, T., Fiszman, S., \& Tárrega, A. (2014). Consumers' hedonic expectations and perception of the healthiness of biscuits made with olive oil or sunflower oil. Food Research International, 55, 197-206.

Tarrega, A., Marcano, J., \& Fiszman, S. (2016). Yogurt viscosity and fruit pieces affect satiating capacity expectations. Food Research International, 89, 574-581.

Tyle, P. (1993). Effect of size, shape and hardness of particles in suspension on oral texture and palatability. Acta Psychologica, 84(1), 111-118.

van Eck, A., Fogliano, V., Galindo-Cuspinera, V., Scholten, E., \& Stieger, M. (2018). Adding condiments to foods: How does static and dynamic sensory perception change when bread and carrots are consumed with mayonnaise? Food Quality and Preference, $1-17$.

van Eck, A., Hardeman, N., Karatza, N., Fogliano, V., \& Scholten, E. (2019). Oral processing behavior and dynamic sensory perception of composite foods : Toppings assist saliva in bolus formation. Food Quality and Preference, 71, 497-509. 